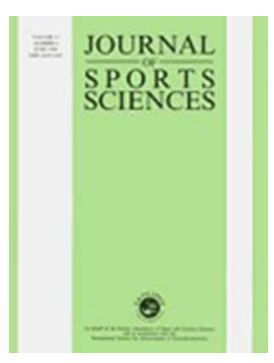

\title{
THE EFFECT OF BREAST SUPPORT AND BREAST PAIN ON UPPER-EXTREMITY KINEMATICS DURING RUNNING: IMPLICATIONS FOR FEMALES WITH LARGE BREASTS
}

\begin{tabular}{|r|l|}
\hline Journal: & Journal of Sports Sciences \\
\hline Manuscript ID: & RJSP-2014-0681.R2 \\
\hline Manuscript Type: & Original Manuscript \\
\hline Keywords: & Kinematics, Biomechanics, Pain, Bra, Peformance \\
\hline \multicolumn{2}{|}{} \\
\hline
\end{tabular}

SCHOLARONE $^{\text {Ix }}$

Manuscripts 


\author{
Title \\ THE EFFECT OF BREAST SUPPORT AND BREAST PAIN ON UPPER- \\ EXTREMITY KINEMATICS DURING RUNNING: IMPLICATIONS FOR \\ FEMALES WITH LARGE BREASTS
}

\title{
Running Title \\ Effect of breast support on running kinematics
}

Keywords

Kinematics; Biomechanics; Pain; Bra; Performance 
Abstract

The relationship between inappropriate breast support and upper-extremity kinematics for female runners is unclear. The purpose of this study was to investigate the effect of breast support and breast pain on upper-extremity kinematics during running. Eleven female recreational runners with larger breasts (UK D to E cup) completed a 7 min $20 \mathrm{~s}$ treadmill run $\left(2.58 \mathrm{~m} . \mathrm{s}^{-1}\right)$ in a high and low breast support condition. Multi-planar breast and upper-extremity kinematic data were captured in each breast support condition by eight infrared cameras for $30 \mathrm{~s}$ towards the end of the run. Breast pain was rated at the end of each treadmill run using a numeric analogue scale. The high support bra reduced breast kinematics and decreased breast pain $(\mathrm{p}<0.05)$. Upper-extremity kinematics did not differ between breast support conditions $(\mathrm{p}>0.05)$, although some moderate positive correlations were found between thorax ROM and breast kinematics $(r=0.54$ to 0.73$)$. Thorax and arm kinematics do not appear to be influenced by breast support level in female runners with large breasts. A high support bra that offers good multi-planar breast support is recommended for female runners with larger breasts to reduce breast pain.

\section{Introduction}

After swimming and going to the gym, running is the most popular activity for female recreational athletes in the UK (Sport England, 2011). The benefits of exercise for general health and well-being are well documented and encouragingly female participation in running at a recreational level has been increasing (Sport England, 2011). Unique to the female athlete is the challenge of reducing undesirable breast motion during running, which is more of an issue for women with larger 
breasts (Lorentzen \& Lawson, 1987; McGhee, Steele, Zealey \& Takacs, 2012). A reduction in magnitude of breast kinematics and a decrease in breast pain have been found during running when wearing a sports bra (high support) compared to an everyday bra (low support) (Mason, Page \& Fallon, 1999; Scurr, White \& Hedger, 2010; White, Scurr \& Smith, 2009).

Despite an increasing number of studies investigating the effect of breast support on breast kinematics and breast pain during short duration running (Scurr et al., 2010; White et al., 2009), no empirical studies have been published that explore the effect of breast support and breast pain on the kinematics of sporting activity. Due to the position of the breasts on the thorax it is important to consider how the movement of this additional mass may influence the kinematics of the upper-extremities during running, especially in women with larger breasts and the implications for running performance. Assessing thorax and arm kinematics enables understanding of whether the high magnitude of force acting anteriorly to the thorax (due to breast weight) could affect thorax movements differently depending on the breast support worn and how much pain is felt.

Trunk and arm movements have received less attention in the running literature, although some links have been established between upper-extremity kinematics and running economy (Arellano \& Kram, 2014; Dallam et al., 2005; Hinrichs, 1990; Tseh et al., 2008; Williams \& Cavanagh, 1987). Excessive trunk rotation, flexion and extension are proposed to be mechanical flaws in running style (Messier \& Cirillo, 1989). Lower vertical displacement of the trunk has been linked to increased running economy (Tseh et al., 2008; Williams \& Cavanagh, 1987), although conversely 
Dallam et al. (2005) reported that a reduced vertical trunk displacement led to a decrease in running economy. There is some evidence that vertical trunk displacement decreases with reduced breast support (Boschma, 1994; Mutter, Geyssant, Jeannin, Chaux \& Belli, 2002), speculated to be in response to higher breast pain. Further investigation of this phenomenon is warranted as the relationship between breast pain and/or breast movement and vertical trunk displacement is currently unclear, which may have implications for running performance.

Arms should be held low and relaxed during running (Hinrichs, 1990) with an optimum elbow angle of $\sim 90^{\circ}$. Tartaruga et al. (2012) reported a better running economy with increased elbow range of motion (ROM), although excessive arm rotation has been linked to poor running economy (Williams \& Cavanagh, 1987). The influence of breast support on arm swing mechanics during running is not clear. In a preliminary investigation Boschma (1994) reported no difference in arm angle ROM between breast support conditions in a population of runners with smaller breasts (B and C cup). However, higher breast pain reported for women with larger breasts during running (Lorentzen \& Lawson, 1987) may encourage an altered arm position, a notion proposed by White, Scurr and Hedger (2011) based on subjective feedback from UK D cup size female runners in their study. It is anticipated that if increased breast movement and pain is experienced by runners with larger breasts this may lead them to reduce their torso rotation, which can be achieved by adopting a greater arm swing (Arellano \& Kram, 2014). A more cross-over style arm swing may also be adopted in an attempt to be more comfortable, which reduces side-toside motion of the whole body (Arellano \& Kram, 2014). 
Increased breast pain in female runners with larger breasts is likely to result from a greater breast mass causing larger forces to act, e.g. for a 34 DD cup (UK size) female athlete their breasts will add an estimated 1150 grams in mass to the thorax segment (Turner \& Dujon, 2005). Based on research into gait parameter changes following breast reduction or mastectomy it is reasonable to assume that this additional mass may subsequently influence running mechanics, as improved biomechanical characteristics of gait and static balance have been found following reduction mammoplasty (Goulart et al., 2013; Montezuma et al., 2014). Furthermore, the use of a front pack with loads of $10 \%$ and $15 \%$ of body weight was found to alter walking mechanics, with the use of a front pack resulting in a more upright gait posture compared to a backpack of similar load (Fiolkowski et al., 2006), suggesting increased breast mass may affect mechanics.

There is limited evidence linking biomechanical parameters to optimum running performance, which has been attributed to the high between-participant variability in running mechanics (Williams, 1985). However, if female runners with large breasts wear bras that are not appropriate for the demands of running (i.e. they experience high levels of breast movement and breast pain) alterations in upper-extremity running kinematics could occur in an attempt to mitigate these changes. There is rationale to explore changes in upper-extremity kinematics that breast support and breast pain may induce to ascertain whether there could be implications for performance.

The aim of this study was to investigate the effect of a high and low breast support condition and breast pain on upper-extremity kinematics in female runners with large 
breasts. It was hypothesised that 1) the sports bra would significantly reduce breast kinematics and breast pain compared to the everyday bra, providing a definitive high and low breast support condition (respectively), 2) there would be significant differences in upper-extremity kinematic variables between the high and low breast support condition, and 3) significant correlations would be found between breast kinematics, breast pain and upper-extremity kinematic variables.

\section{Methods}

Eleven female recreational athletes with larger breasts (bra sizes ranged between a UK 32 to 34 band size and a D to E cup size), who participated in 30 minutes of sport at a moderate intensity 3 times a week but did not follow a professionally designed training regime and were familiar with treadmill running, were selected (mean (SD): age 26 (7) years, height $1.66(0.04) \mathrm{m}$, mass 64.31 (6.38) kg). Pregnancy, breast feeding and breast surgery cause changes to the breast (McCool, Stone-Condry \& Bradford, 1998; Page \& Steele, 1999) so participants were excluded if they were pregnant, had breast-fed within the last year or had previously undergone breast surgery. Institutional ethical approval was given by the BioSciences Research Ethics Committee, complying with the Deceleration of Helsinki (2000) and the Council of Europe (2005) guidelines on human rights and biomedicine concerning biomedical research.

Participants were bra fitted using professional best-fit criteria (McGhee \& Steele, 2010; White \& Scurr, 2012). As the menstrual cycle affects breast size and breast pain (McCool et al., 1998; Milligan, Drife \& Short, 1975), for consistency all participants were tested between the end of menstruation and the start of the luteal 
phase of their menstrual cycle (day 4 to 15 ) when the breast is reported to be at its lowest and most stable size (Milligan et al., 1975). Participants were asked to wear their own running trainers. Participants completed a 5-minute treadmill $(\mathrm{h} / \mathrm{p} / \mathrm{cosmos}$ mercury, Germany) warm-up at a self-selected pace, followed by static stretching. Next participants were asked to put on either an everyday bra (plain, non-padded, underwired t-shirt bra, made from 78\% Polyamide and 22\% Elastane; Marks \& Spencer ${ }^{\mathrm{TM}}$ ) or a sports bra (non-wired, made from $45 \%$ Polyester, $44 \%$ Polyamide and 11\% Elastane; B4990, Shock Absorber $\left.{ }^{\mathrm{TM}}\right)$. This everyday bra was chosen as the 'low support' condition as it was similar to those tested in previous studies (Scurr et al., 2010; White et al., 2011), which had been reported to reduce less breast displacement when compared to a sports bra; the sports bra chosen as the 'high support' condition was the current best-selling sports bra on the UK market (Personal Communication, 2011).

All participants ran at a treadmill velocity of $2.58 \mathrm{~m} \cdot \mathrm{s}^{-1}$ for 7 minutes and $20 \mathrm{~s}$; although the exact duration was dictated by a concurrent study, a minimum of 5 minutes was chosen to concur with Boschma's (1994) study and was deemed a sufficient amount of time to provoke breast pain after pilot testing. Each participant completed the treadmill run in the low and high support condition in a random order on the same day, with a rest period of at least 10 minutes between runs. Multi-planar kinematic data were captured by eight infrared cameras $(200 \mathrm{~Hz}$; Oqus 300 , Qualisys, Sweden) positioned around the treadmill. A thirty second data capture between 6 minutes $30 \mathrm{~s}$ and 7 minutes enabled five complete stride cycles (i.e. right foot contact to right foot contact) to be analysed (Scurr et al., 2010). Participants rated breast pain after each treadmill run using a numeric analogue scale (Mason et 
al., 1999) with 10 increments, where 0 represented comfortable (no pain), 5 represented uncomfortable and 10 represented painful.

For breast and thorax kinematic analysis 5 markers (7 mm; Qualysis, Sweden) were placed on the suprasternal notch, right nipple (on the bra, directly over the nipple; Mason et al., 1999; White et al., 2009) and the anterioinferior aspect of the 10th left and right rib (Scurr et al., 2010). To calculate right upper-extremity kinematics additional markers were placed on the acromion process, lateral epicondyle of the humerus and radius styloid process to calculate upper arm ROM and mean elbow angle; the right heel of the trainer (lateral border) was used to distinguish stride cycles as all participants were observed as being rearfoot strikers.

Markers were identified and multi-planar data reconstructed in Qualysis Track Manager software (version 2.7, Qualisys, Sweden), with tracking parameters of 0.30 mm marker detection error and a maximum interpolation of 10 frames. All raw kinematic data were filtered using a second order recursive Butterworth filter (MatLab version R2010a; cut off frequencies 10 to $13 \mathrm{~Hz}$ determined by visually assessing the power density spectrum). To establish relative breast kinematics, independent to the thorax, an orthogonal local coordinate system converted absolute right nipple coordinates to relative coordinates using a transformation matrix (Scurr et al., 2010). Utilising the transformed nipple coordinates, minima positional coordinates were subtracted from maxima coordinates in each stride cycle to calculate breast displacement $(\mathrm{m})$. First (breast velocity, $\mathrm{m} . \mathrm{s}^{-1}$ ) and second (breast acceleration, $\mathrm{m} . \mathrm{s}^{-2}$ ) derivatives of breast displacement were calculated 
instantaneously for each sample $(0.005 \mathrm{~s})$ with peak values recorded for each stride cycle.

Anterioposterior right heel marker velocity data were used to determine footstrike events (Zeni, Richards \& Higginson, 2008). The suprasternal notch was used to represent vertical thorax motion (Haake \& Scurr, 2010); the time history of the vertical coordinate data was plotted and the minima were subtracted from the maxima for the five stride cycles to determine the mean vertical thorax displacement (m). The time (s) between consecutive minima points (one complete cosine wave) was recorded; to determine the vertical thorax frequency $(\mathrm{Hz}) 1$ was divided by the time taken.

Two-dimensional thorax segment angles relative to each viewing plane were calculated with respect to the global vertical or mediolateral axis (segment neutral position was zero degrees when aligned with the respective global axis). Markers on the acromion process and lateral epicondyle of the humerus were used to calculate upper arm $\mathrm{ROM}\left(^{\circ}\right)$ relative to the thorax in the sagittal and frontal planes. The range between maxima and minima points in each stride cycle (averaged over five stride cycles) defined the $\mathrm{ROM}^{\circ}$ for the thorax and upper arm segment angles. Markers on the right acromion process, right lateral epicondyle of the humerus and the right radius styloid process were used to calculate a mean two-dimensional intersegment angle at the elbow at each sample (Messier \& Cirillo, 1989).

Data were first checked for normality using Kolmogorov-Smirnov and ShapiroWilks tests and parametric assumptions assumed where $\mathrm{p}>0.05$ for both tests. 
Paired samples t-tests examined differences in kinematic variables between low and high support conditions (alpha level of 0.05 ), 95\% confidence intervals (CI) and within-participant and between-participant coefficient of variance (CV\%) are presented where appropriate. Pearson $\left(\mathrm{r}_{\mathrm{p}}\right)$ correlation coefficients (or Spearman's correlation coefficients $\left(r_{s}\right)$ if data were not parametric) examined relationships between breast kinematics, breast pain and upper-extremity kinematic variables ( $\mathrm{r}>$ $0.50=$ moderate relationship; $r>0.70=$ strong relationship; Fallowfield, Hale \& Wilkinson, 2005).

\title{
2. Results
}

Breast displacement in all directions, vertical and anterioposterior breast velocity and vertical acceleration were significantly greater $(\mathrm{p}<0.05 ; d=1.21$ to 1.96$)$ in the low breast support compared to the high breast support condition (Figure 1).

\footnotetext{
$* * * *$ Figure 1 near here ${ }^{* * * *}$
}

\begin{abstract}
All upper-extremity kinematic variables measured did not differ significantly $(\mathrm{p}>$ $0.05 ; d=0.02$ to 0.41 ) between breast support conditions (Table 1). Withinparticipant $\mathrm{CV} \%$ were considered high $(>10 \%)$ for thorax $\mathrm{ROM}$ in the frontal and sagittal plane and upper arm ROM in the frontal plane in each support condition (Table 1). Between-participant CV\% was low for vertical thorax displacement and frequency and mean elbow angle $(<10 \%)$ but was considered high for thorax and upper arm ROM (range: $13.19 \%$ to $37.70 \%$ ).
\end{abstract}

****Table 1 near here $* * * *$ 
The high breast support condition was most frequently rated as 'no pain' (mode: 0 , range: 0 to 2) whilst running in the low breast support condition was rated significantly higher $(\mathrm{p}<0.01)$ and most frequently reported as being between 'uncomfortable' and 'painful' (mode: 7, range: 0 to 8) for the breast. Relationships were explored between upper-extremity kinematic variables, breast kinematics and breast pain when data were grouped together (i.e. not separated into low and high support conditions) (Table 2). Breast displacement, velocity and acceleration displayed significant $(\mathrm{p}<0.01)$ moderate to strong correlations to breast pain. Breast pain was most highly correlated with anterioposterior breast kinematics (mean correlation of $r=0.75)$.

Relationships were found for two upper-extremity variables; mediolateral breast velocity related positively to thorax ROM in the sagittal plane $\left(r_{p}=0.54, p=0.04\right)$ and thorax ROM in the frontal plane related positively to anterioposterior breast acceleration $\left(r_{s}=0.73, p=0.01\right)$ and mediolateral breast acceleration $\left(r_{p}=0.61, p=\right.$ 0.02). Breast pain did not correlate to any upper-extremity variables $(\mathrm{p}<0.05)$.

$* * * *$ Table 2 near here $* * * *$

\section{Discussion}

This was the first research to investigate the effect of breast support and breast pain on upper-extremity kinematics in a population of female runners with larger breasts. Significant differences found in breast kinematics between the two bras tested (Figure 1) compared well to previous studies (Scurr et al., 2010; White et al., 2009) 
and provided a definitive high and low breast support condition that could be utilised to investigate the effect of breast support on upper-extremity running kinematics, accepting the first hypothesis. Breast acceleration was much higher in this study (up to $\left.41 \mathrm{~m} . \mathrm{s}^{-2}\right)$ than previously reported $\left(\sim 20 \mathrm{~m} . \mathrm{s}^{-2}\right.$ to $\sim 27 \mathrm{~m} . \mathrm{s}^{-2}$; Mason et al., 1999, Scurr et al., 2010) for runners with smaller breasts (B to D cup), highlighting the high breast forces that occur during running in athletes with larger breasts. The high breast support condition was also rated as significantly less painful during running $(\mathrm{p}<$ 0.02), confirming earlier findings (Mason et al., 1999; Scurr et al., 2010; White et al., 2009), and emphasising the importance of investigating the effect of this additional breast movement and pain on upper-extremity kinematics when poor breast support is worn.

Feedback from participants in previous research suggested that changes occur in upper-extremity movements when breast support is altered (White et al., 2011). Boschma (1994) found no difference in arm ROM between breast support conditions, yet this was for a population of females with smaller breasts. Investigation into the movement of the upper-extremity was warranted in females with larger breasts. No differences in arm or thorax kinematics were however reported between breast support conditions (Table 1), suggesting that there are no adverse performance implications when low breast support is worn for the upperextremity variables measured in this study. Although, high between-participant CV\% was found for upper-extremity variables (up to $38 \%$ ), highlighting the individual nature of running gait. 
It was proposed that vertical thorax displacement would be less during the low breast support condition based on previous research (Boschma, 1994; Mutter et al., 2002), which had speculated reduced displacement occurs due to increased breast pain. Although vertical thorax displacement did not significantly differ between breast support conditions when group mean data were examined $(\mathrm{p}>0.05 ; d=-0.15)$, displacement was up to $1 \mathrm{~cm}$ less in the low support condition for some individuals, which could have been a response to the increased breast pain found in this condition. However, within-participant variation was considered low for this variable $(<10 \mathrm{CV} \%)$ and there was no change in vertical thorax frequency, which suggests temporal-spatial parameters did not change due to the level of breast support. It would be useful to explore whether an increased run duration or velocity, i.e. placing the participants under greater stress, may lead to noteworthy differences in upperextremity variables between breast support conditions. This is especially important to consider as there may be a minimum duration where increased perceived breast pain in the low breast support condition may start affecting running style; future research could assess the same variables over a longer distance.

It was thought that the participant's arms may have been held higher whilst participants were running with lower breast support in an attempt to reduce breast movement and pain. However, mean elbow angle was $71.59^{\circ}$ and $70.32^{\circ}$ for the low and high breast support condition (respectively), suggesting no conscious change occurred in how the arms were held. These angles were much lower than the $90^{\circ}$ recommended by Hinrichs (1990) though, and suggests arms were carried quite high in both conditions; this may be reflective of a non-relaxed running gait due to the nature of this study, i.e. participants may have felt embarrassed running in their bra 
in the lab setting. Embarrassment of breast movement has been found to be a barrier to exercise for some women (Burnett, White \& Scurr, 2014).

Thorax displacement is the driving force for breast motion (Haake \& Scurr, 2010) so unsurprisingly some relationships were found between breast kinematics and thorax ROM in the sagittal and frontal planes (Table 2). It is unclear whether participants who have greater thorax ROM in the sagittal and frontal planes are stimulating increases in breast kinematic variables or if increased breast kinematics are stimulating greater thorax ROM. However, if an individual's running kinematics (i.e. how much thorax ROM they have whilst running) influences their breast kinematics, then it could be speculated that runners' with greater thorax ROM would require greater breast support. This suggestion promotes the idea of individual analyses of participants, with the potential for custom-made sports bras for runners with larger breasts, although further research is warranted.

Interestingly, the strongest relationships between breast kinematics and breast pain were found in the anterioposterior direction (Table 2), as anterioposterior breast kinematics increased so did breast pain. This is contrary to previous research that has found the strongest relationships between vertical breast velocity and breast pain (McGhee, Steele \& Power, 2007; Scurr et al., 2010) or vertical breast displacement and breast pain (Mason et al., 1999; White et al., 2009) and was surprising, as most breast displacement, velocity and acceleration occurred in the vertical direction during running (Figure 1). The exact mechanism of exercise-induced breast pain is unknown, although it is thought to be related to strain on the delicate tissues that help support the breast (the skin and Cooper's ligaments) (Page \& Steele, 1999). 
Anterioposterior breast displacement during running results in the breast being pulled away from the chest wall (tension force), then compressing quickly and repetitively against it. The reduction of anterioposterior breast kinematics is therefore an important consideration for sports bra design due to the close association with breast pain. It is however acknowledged that participants may be partially biased to breast pain ratings in this study as breast support conditions were unable to be blinded.

This is the first research to investigate the effect of breast support and breast pain on upper-extremity kinematics in a population of runners with larger breasts. In conclusion, the upper-extremity kinematic variables assessed in this study did not significantly differ between breast support conditions, suggesting there are no performance implications if low breast support is worn for running, although individual variance was high. As positive relationships were found between thorax ROM and breast kinematics it is proposed that an individual's running style may influence the amount of breast motion that occurs and custom-made breast support could be necessary, although further research is advised. Sports bra designers should consider the reduction of breast motion in the anterioposterior direction to help reduce breast pain for female runners with larger breasts. The use of a well-fitted high support bra for women with larger breasts when running at a constant velocity is recommended based on the findings of this study.

\section{References}

Arellano, C. J., \& Kram, R. (2014). The metabolic cost of human running: is swinging the arms worth it? The Journal of Experimental Biology, 217, 2456-2461. 
Boschma, A. L. C. (1994). Breast support for the active woman: relationship to 3D kinematics of running. Unpublished masters thesis, Oregon State University, Oregon.

Burnett, E., White, J., \& Scurr, J. (2014). The influence of the breast on physical activity participation in females. Journal of Physical Activity \& Health, DOI: 10.1123/jpah.2013-0236.

Cavanagh, P. R., \& Kram, R. (1990). Stride Length in distance running: velocity, body dimensions, and added mass effects. In P. R. Cavanagh (Ed.), Biomechanics of Distance Running (pp. 35-63). Champaign, IL: Human Kinetics.

Dallam, G. M., Wilber, R. L., Jadelis, K., Fletcher, G., \& Romanov, N. (2005).

Effect of a global alteration of running technique on kinematics and economy. Journal of Sports Sciences, 23(7), 757-764.

Fallowfield, J.L., Hale, B.J. \& Wilkinson, D.M. (2005). Using Statistics in Sport and Exercise Science Research. Chichester, England: Lotus Publishing.

Fiolkowski, P., Horodyski, M., Bishop, M., Williams, M., \& Stylianou, L. (2006). Changes in gait kinematics and posture with the use of a front pack. Ergonomics, 49(9), 885-894.

Goulart Jr, R., Schütz, G. R., Detanico, D., Vasconceloos, R., P., \& Giovana dos Santos, S. (2013). Effects of reduction mammoplasty on the static balance and biomechanics of gait. European Journal of Plastic Surgery, 36, 225-230. 
Haake, S., \& Scurr, J. (2010). A dynamic model of the breast during exercise. Sports Engineering, 12(4), 189-197.

Hinrichs, R. N. (1990). Upper Extremity Function in Distance Running. In P. R. Cavanagh (Ed.), Biomechanics of Distance Running (pp. 107-133). Champaign, IL: Human Kinetics.

Lorentzen, D., \& Lawson, L. (1987). Selected sports bras: A biomechanical analysis of breast motion while jogging. The Physician and Sportsmedicine, 8, 89-96.

Mason, B. R., Page, K., \& Fallon, K. (1999). An analysis of movement and discomfort of the female breast during exercise and the effects of breast support in three cases. Journal of Science and Medicine in Sport, 2(2), 134-144.

McCool, W. F., Stone-Condry, M., \& Bradford, H. M. (1998). Breast health care: a review. Journal of Nurse-Midwifery, 43(6), 406-430.

McGhee, D. E., \& Steele, J. R. (2010). Optimising breast support in female patients through correct bra fit: A cross-sectional study. Journal of Science and Medicine in Sport, 13(6), 568-572.

McGhee, D. E., Steele, J. R., \& Power, B. M. (2007). Does deep water running reduce exercise-induced breast discomfort? British Journal of Sports Medicine, 41, 879-883. 
McGhee, D. E., Steele, J. R., Zealey, W. J., \& Takacs, G. J. (2012). Bra-breast forces generated in women with large breasts while standing and during treadmill running: Implications for sports bra design. Applied Ergonomics, 44(1), 112-118.

Messier, S. P., \& Cirillo, K. J. (1989). Effects of a verbal and visual feedback system on running technique, perceived exertion and running economy in female novice runners. Journal of Sports Sciences, 7, 113-126.

Milligan, D., Drife, J. O., \& Short, R. V. (1975). Changes in breast volume during normal menstrual cycle and after oral contraceptives. British Medical Journal, 4, 494-496.

Montezuma, T., de Oliveira Guirro, E. C., Leite, M. M. D. O. L., \& Vernal, S. (2014). Changes in Postural Control in Mastectomized Women. Journal of Cancer Therapy, 5(06), 493.

Mutter, E, Geyssant, A., Jeannin, T., Chaux, C., \& Belli, A. (2002). Influence of brassiere on breast vertical acceleration during running. In M. Koskolou, N. Geladas, \& V. Klissouras (Eds.), Proceedings of the 7th Annual Congress of the ECSS (pp. 312), 24-28 July 2002, Athens, Greece.

Page, K., \& Steele, J. R. (1999). Breast motion and sports brassiere design. Sports Medicine, 27(4), 205-211 
Scurr, J. C., White, J. L., \& Hedger, W. (2010). The effect of breast support on the kinematics of the breast during the running gait cycle. Journal of Sports Sciences, 28(10), 1103-1109.

Sport England. (2011). Active People Survey 2010/11. Retrieved from: http://www.sportengland.org/research/active_people_survey/aps5.aspx

Tartaruga, M. P., Brisswalter, J., Peyré-Tartaruga, L. A., Ávila, A. O. V., Alberton, C. L., Coertjens, M., ... \& Kruel, L. F. M. (2012). The relationship between running economy and biomechanical variables in distance runners. Research Quarterly for Exercise and Sport, 83(3), 367-375.

Tseh, W., Caputo, J. L., \& Morgan, D. W. (2008). Influence of gait manipulation on running economy in female distance runners. Journal of Sports Science \& Medicine, 7(1), 91.

Turner, A. J., \& Dujon, D. G. (2005). Predicting cup size after reduction mammaplasty. British Journal of Plastic Surgery, 58, 290-298.

White, J., \& Scurr, J. (2012). Evaluation of professional bra fitting criteria for bra selection and fitting in the UK. Ergonomics, 55(6), 704-711.

White, J., Scurr, J., \& Hedger, W. (2011). A comparison of three-dimensional breast displacement and breast comfort during overground and treadmill running. Journal of Applied Biomechanics, 27, 47-53. 
White, J., Scurr, J., \& Smith, N. (2009). The effect of breast support on kinetics during overground running performance. Ergonomics, 52(4), 492-498.

Williams, K. R. (1985). Biomechanics of Running. Exercise and sport sciences review, 13(1), 389-442.

Williams, K. R., \& Cavanagh, P. R. (1987). Relationship between distance running mechanics, running economy, and performance. Journal of Applied Physiology, 63(3), 1236-1245.

Zeni Jr., J. A., Richards, J. G., \& Higginson, J.S. (2008). Two simple methods for determining gait events during treadmill and overground walking using kinematic data. Gait \& Posture, 27, 710-714. 
1

2

3

4

5

6

7

8

9

10

11

12

13

14

15

16

17

18

19

20

21

22

23

24

25

26

27

28

29

30

31

32

33

34

35

36

37

38

39

40

41

42

43

44

45

46

47

48

49

50

51

52

53

54

55

56

57

58

59

60
Table 1

Mean (SD) upper-extremity kinematics over five stride cycles during running at 2.58

$\mathrm{m} . \mathrm{s}^{-1}$ in the low and high breast support conditions $(\mathrm{n}=11)$ with $95 \% \mathrm{CI}$ and effect sizes $(d)$.

Table 2

Relationships (r) between breast kinematics, breast pain and upper-extremity kinematics $(\mathrm{n}=11), *$ denotes a significant relationship $(\mathrm{p}<0.05)$

Figure 1

Mean (SD) breast displacement (m), velocity $\left(\mathrm{m} . \mathrm{s}^{-1}\right)$ and acceleration $\left(\mathrm{m} . \mathrm{s}^{-2}\right)$ in all directions between the high and low support conditions over five stride cycles during running at $2.58 \mathrm{~m} . \mathrm{s}^{-1}(\mathrm{n}=11), *=$ significant difference $(\mathrm{p}<0.05)$ 


\begin{tabular}{|c|c|c|c|c|c|}
\hline & Lov & port & & & \\
\hline & Mean (SD) & $95 \% \mathrm{CI}$ & Mean (SD) & $95 \%$ CI & Effect size $(d)$ \\
\hline Vertical thorax displacement (m) & $0.10(0.01)$ & 0.09 to 0.10 & $0.10(0.01)$ & 0.10 to 0.11 & -0.15 \\
\hline Vertical thorax frequency $(\mathrm{Hz})$ & $2.66(0.06)$ & 2.62 to 2.71 & $2.66(0.08)$ & 2.60 to 2.71 & 0.12 \\
\hline Thorax ROM (transverse plane) $\left(^{\circ}\right)$ & $24.72(9.32)$ & 18.46 to 30.98 & $25.46(8.55)$ & 19.72 to 31.21 & 0.13 \\
\hline Thorax ROM (frontal plane) $\left(^{\circ}\right)$ & $8.21(2.46)$ & 6.56 to 9.86 & $8.16(2.09)$ & 6.76 to 9.56 & 0.02 \\
\hline Thorax ROM (sagittal plane) $\left(^{\circ}\right)$ & $7.48(1.24)$ & 6.64 to 8.32 & $7.01(1.07)$ & 6.29 to 7.73 & 0.41 \\
\hline Mean elbow angle $\left(^{\circ}\right)$ & $71.59(5.70)$ & 67.73 to 75.45 & $70.32(6.19)$ & 66.69 to 73.94 & 0.21 \\
\hline Upper arm ROM (frontal plane) $\left({ }^{\circ}\right)$ & $13.96(3.79)$ & 11.42 to 16.51 & $14.13(4.82)$ & 10.89 to 17.37 & 0.06 \\
\hline Upper arm ROM (sagittal plane) $\left(^{\circ}\right)$ & $68.78(10.90)$ & 61.46 to 76.11 & $70.44(9.29)$ & 64.20 to 76.68 & 0.25 \\
\hline
\end{tabular}




\begin{tabular}{|c|c|c|c|c|c|c|c|c|c|c|}
\hline & $\begin{array}{c}\text { a/p Disp } \\
\text { (m) }\end{array}$ & $\begin{array}{c}\text { a/p Vel } \\
\left(\mathrm{m}^{-s^{-1}}\right)\end{array}$ & $\begin{array}{c}\text { a/p Acc } \\
\left(\mathbf{m} \cdot \mathrm{s}^{-2}\right)\end{array}$ & $\begin{array}{c}\text { m/l Disp } \\
\text { (m) }\end{array}$ & $\begin{array}{c}\mathrm{m} / \mathrm{l} \mathrm{Vel} \\
\left(\mathrm{m} \cdot \mathrm{s}^{-1}\right)\end{array}$ & $\begin{array}{c}\mathrm{m} / \mathrm{l} \mathrm{Acc} \\
\left(\mathrm{m} . \mathrm{s}^{-2}\right)\end{array}$ & $\begin{array}{l}\text { Vertical } \\
\text { Disp (m) }\end{array}$ & $\begin{array}{c}\text { Vertical } \\
\text { Vel } \\
\left(\mathrm{m}^{-1} \mathbf{s}^{-1}\right)\end{array}$ & $\begin{array}{c}\text { Vertical } \\
\text { Acc } \\
\left(\mathrm{m}^{-2} \mathbf{s}^{-2}\right)\end{array}$ & $\begin{array}{c}\text { Breas } \\
\text { Pain } \\
(/ 10)\end{array}$ \\
\hline Vertical thorax displacement (m) & -0.26 & -0.14 & -0.20 & -0.01 & 0.02 & 0.14 & -0.15 & 0.06 & 0.20 & -0.25 \\
\hline Vertical thorax frequency $(\mathrm{Hz})$ & 0.27 & 0.25 & 0.24 & 0.05 & -0.19 & -0.04 & 0.26 & 0.17 & 0.21 & 0.01 \\
\hline Thorax ROM (transverse plane) $\left({ }^{\circ}\right)$ & 0.01 & 0.30 & 0.31 & 0.22 & 0.12 & 0.42 & 0.41 & 0.16 & -0.09 & 0.03 \\
\hline Thorax ROM (frontal plane) $\left({ }^{\circ}\right)$ & 0.33 & 0.49 & $0.73 *$ & 0.22 & 0.38 & $0.61^{*}$ & 0.25 & 0.15 & 0.03 & 0.36 \\
\hline Thorax ROM (sagittal plane) $\left(^{\circ}\right)$ & 0.12 & 0.14 & -0.18 & 0.07 & $0.54 *$ & 0.30 & -0.07 & -0.06 & -0.13 & 0.36 \\
\hline Mean elbow angle $\left({ }^{\circ}\right)$ & 0.24 & 0.01 & -0.019 & -0.07 & -0.38 & -0.26 & 0.23 & 0.20 & 0.07 & 0.25 \\
\hline Upper arm ROM (frontal plane) $\left({ }^{\circ}\right)$ & 0.02 & 0.03 & -0.01 & 0.26 & -0.01 & -0.07 & 0.07 & 0.15 & 0.17 & 0.17 \\
\hline Upper arm ROM (sagittal plane) $\left({ }^{\circ}\right)$ & 0.03 & 0.01 & 0.28 & -0.30 & -0.05 & 0.08 & 0.14 & -0.03 & -0.07 & 0.27 \\
\hline Breast Pain (/10) & $0.75^{*}$ & $0.72 *$ & $0.79 *$ & $0.74 *$ & $0.59 *$ & $0.62 *$ & $0.62 *$ & $0.62 *$ & $0.55^{*}$ & - \\
\hline
\end{tabular}



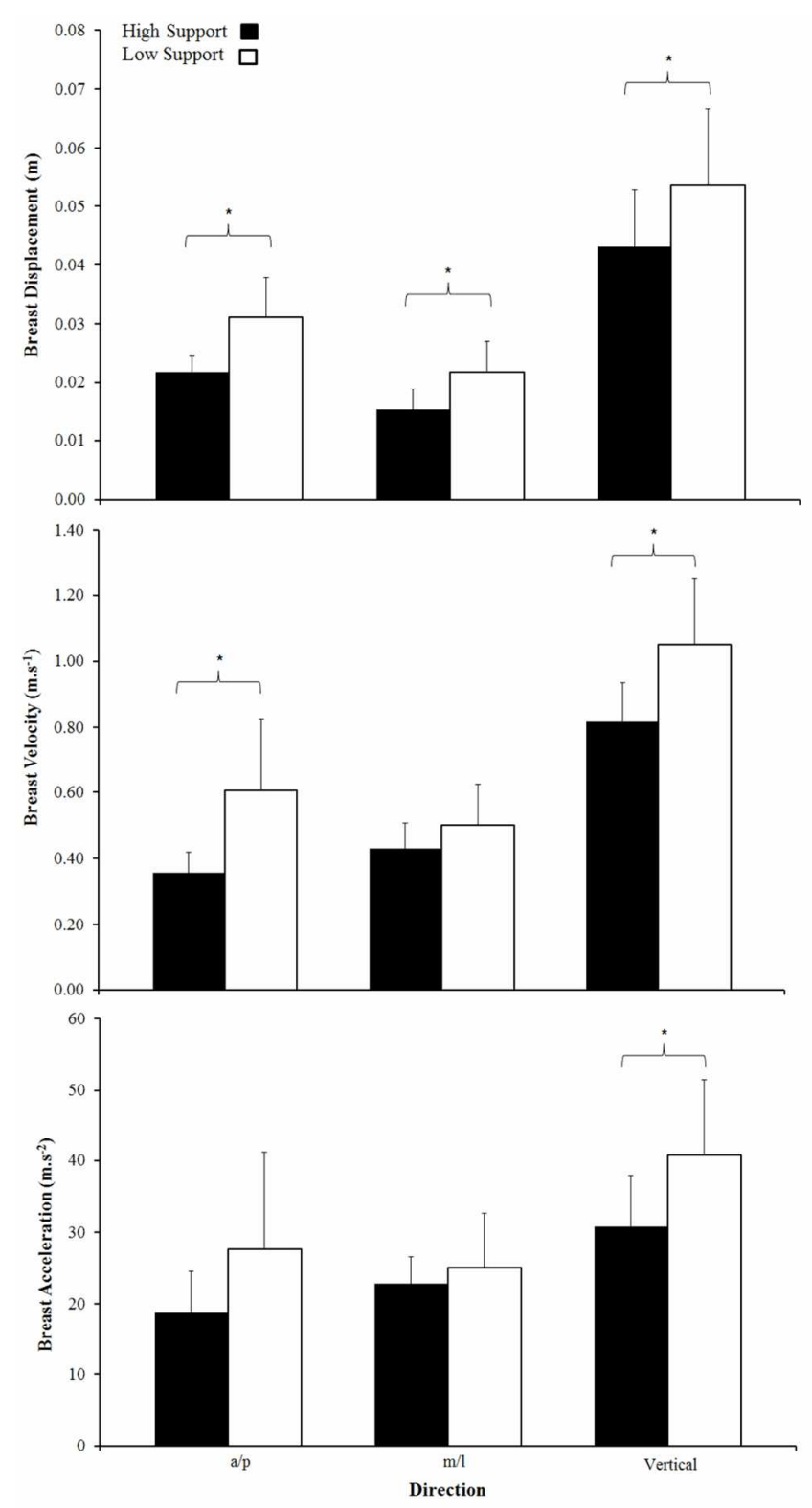

$88 \times 166 \mathrm{~mm}(300 \times 300$ DPI $)$ 